\title{
Preparing for College: A Day Long Conference for Students, Parents, and Professionals
}

Recognized as a world leader in research and clinical work in supporting children with autism, Asperger's Disorder, and learning challenges, the Child Study Center of Yale University is pleased to announce a 1 day conference for students (Grades 9-11), their parents, and professionals (teachers, guidance counselors and others) focused on issues of the transition from high school to college.

The day will begin with an introduction and overview for the entire group. Students will then spend their time in a series of sessions devoted to issues focused on selecting a college, challenges and opportunities in college, and a series of smaller workshops aimed at providing practical strategies and information valuable to students. Parents and professionals will have a series of complementary presentations. Topics will include transition issues, accessing services, self-advocacy and life skills, coping with bullying, strategies for academic and personal success, time management and organizational skills. Transitional programs and alternate pathways to college will also be discussed along with mental health challenges and supports.

Speakers will include: Jane Thierfield Brown, E.D. (Director of Student Services at the University of Connecticut School of Law), Lorri Sherry (President-Asperger Syndrome Education Network), Jeffrey Brenzel, PhD. (Dean of Admissions for Yale College), Ernst VanBergeijk, Ph.D.,
M.S.W. (Associate Dean and Executive Director of the Vocational Independence Program, New York Institute of Technology), and Michael Storz (President, Chapel Haven) as well as presenters from the Yale Child Study Center (including Fred Volkmar, M.D., Director, and staff/faculty members including Gwen Lopez-Cohen, M.D., Eli Lebowitz, Ph.D., Kathy Tsatsanis, Ph.D., Kathleen Koenig, MSN, APRN, Julie Wolf, Ph.D., Leah Booth, M.A., CCC-SPL, Roger Jou, M.D., and Alexander Westphal, M.D.).

The conference will be held on April 22, 2012, 10 AM5 PM (registration opens at 9:30 AM). Cost is $\$ 90$ for one parent and one child ( $\$ 120$ for two parents and one child) and $\$ 100$ for professionals. Continental breakfast, lunch, and afternoon snack will be provided.

Location: Harkness Auditorium 333 Cedar Street, New Haven, CT (and at the Child Study Center-same address) - a short distance from the Metro North train station in New Haven (a shuttle bus is available). Hotel accommodations, at the participant's own expense, can be arranged for those wishing to arrive the evening before. Advance registration is required and space may be limited. For additional information including a detailed schedule and to register online, please visit: www.childstudycenter .yale.edu/registerforapril22.aspx. 